\title{
VER O INVISÍVEL: EXPERIMENTAR E REFLETIR A PRÁTICA FOTOGRÁFICA/ANTROPOLÓGICA
}

\author{
SARAH VICTÓRIA ALMEIDA RODRIGUES ${ }^{1}$
}

\begin{abstract}
RESUMO
As reflexões sobre os limites da imagem como experiência fazem com que, contemporaneamente, a fotografia reinvente seus suportes e sua relação com outras mídias, propondo diferentes diálogos e conexões. Nesses novos contextos, a prática fotográfica se amplia, possibilitando experiências sensoriais diversas e convidando 0 corpo. Dessa forma, este trabalho busca refletir sobre a prática fotográfica de corpo inteiro realizada pelas pessoas com deficiências visuais. Nesse exercício, tomando os sentidos como integrados, é possível, portanto, verpor meio da escuta. E mais do que experiências de luz - como elemento que permite que nossos olhos vejam e de som - como aquilo de nossos ouvidos recebem de forma imediata -, as experiências sensórias se contrastam, se cruzam e se localizam em meio ao corpo em movimento não mais como caminhos sensórios diferentes, mas como caminhos complementares. Essas sensorialidades também desembocam no fazer antropológico, apresentando novas proposições teóricas e ferramentas metodológicas para a disciplina.
\end{abstract}

PALAVRAS-ChAVE

Corporalidade; Pensamento sensorial; Antropologia Visual; Novas antropologias

TO SEE THE INVISIBLE: EXPERIENCING AND REFLECTING PHOTOGRAPHIC/ANTHROPOLOGICAL PRACTICE

\begin{abstract}
Reflections on the boundaries of the image as experience lead photography to reinvent its supports and its relation with other media, proposing different dialogues and connections. In these new contexts, the photographic practice expands itself, allowing multiple sensorial experiences and inviting the body. Therefore, this work seeks to reflect on the photographic practice with a whole body did by visually impaired people. In this exercise, taking the senses as integrated, it is possible to see through listening. And more than experiences of light - as an element that enables our eyes to see - and of sound - as our ears receive immediately - sensory experiences are contrasted, intersected, and located in the body in motion not as different sensory paths, but as complementary paths. These sensorialities also lead to the anthropological work, presenting new theoretical propositions and methodological tools for the discipline.
\end{abstract}

\section{KEYWORDS}

Corporality; Sensorial thought; Visual Anthropology; New anthropologies

\section{VOIR L'INVISIBLE: SUR EXPÉRIMENTER ET RÉFLÉCHIR SUR LA PRATIQUE PHOTOGRAPHIQUE /ANTHROPOLOGIQUE}

\begin{abstract}
RÉSUMÉ
Les réflexions sur les frontières de l'image comme expérience font la photographie réinventer ses supports et relation avec les autres médias et proposer des multiples dialogues et connexions. La pratique de la photographie se développe, permet diverses expériences sensorielles et invite le corps dans ces nouveaux contextes. De cette sorte, ce travail chasse à réfléchir sur la pratique photographique avec le corps complète fit
\end{abstract}

\footnotetext{
1 Mestranda pelo Programa de Pós-Graduação em Sociologia e Antropologia da Universidade
} Federal do Rio de Janeiro (PPGSA/IFCS/UFRJ). 
par les malvoyants. Dans cet exercice, en considérant les sens comme intégrés, c'est possible de voir à travers de l'audition. Plus que des expériences de lumière - comme un élément qui permet à nos yeux de voir - et de son ça que nos oreilles reçoivent immédiatement - les expériences sensorielles sont contrastées, croisées et situées par les corps en mouvement. Au lieu des chemins sensoriels différents, ils sont, par contre, des chemins complémentaires. Ces sensorialités conduisent aussi au travail anthropologique, présentant de nouvelles propositions théoriques et des outils méthodologiques pour la discipline.

\title{
MotS CLÉS
}

Corporalité ; Pensée sensorielle ; Anthropologie visuelle ; Nouvelles anthropologies;

\section{VER EL INVISIBLE: SOBRE EXPERIMENTAR Y REFLEXIONAR LA PRÁCTICA FOTOGRÁFICA/ ANTROPOLÓGICA}

\begin{abstract}
RESUMEN
Las reflexiones sobre los límites de la imagen como experiencia hacen que, contemporáneamente, la fotografía reinvente sus soportes y su relación con otros medios, proponiendo diferentes diálogos y conexiones. En estos nuevos contextos, la práctica fotográfica se amplía, posibilitando experiencias sensoriales diversas e invitando al cuerpo. Por lo tanto, este trabajo busca reflexionar sobre la práctica fotográfica de cuerpo entero hecha por las personas con deficiencias visuales. En ese ejercicio, tomando los sentidos como integrados, es posible, por lo tanto, ver por medio de la escucha. Y más que experiencias de luz-como elemento que permite que nuestros ojos vean- y de sonido -como aquello que nuestros oídos reciben de forma inmediata-, las experiencias sensoriales se contrastan, se cruzan y se localizan en medio del cuerpo en movimiento no más como caminos sensorios diferentes, pero como caminos complementarios. Estas sensorialidades también desembocan en el hacer antropológico, presentando nuevas proposiciones teóricas y herramientas metodológicas para la disciplina.
\end{abstract}

\section{Palabras Clave}

Corporeidad; Pensamiento sensorial; Antropología Visual; Nuevas antropologías 


\section{FOTOGRAFAR COM O CORPO INTEIRO: UMA INTRODUÇÃO}

Em 1990, os projetos com a iniciativa de democratização da imagem, em termos de acesso à fotografia e à sua prática, cresceram e se diversificaram, mas suas estratégias e propósitos se manifestaram diferentemente. Esses projetos objetivavam usar a fotografia como "instrumento para a cidadania, em busca da valorização da autoestima e da leitura crítica do mundo" (MENDES, 2005, p. 75). A partir dos anos 2000, as iniciativas de inclusão visual, sejam no campo da fotografia ou do audiovisual, vêm sendo difundidas e se multiplicando em sua execução, ação que também tem ocorrido com frequência em países considerados periféricos, como Argentina, França, México, África do Sul, Arábia Saudita, Brasil, Índia, Itália, Holanda, Bangladesh, Haiti e Jerusalém (GAMA, 2009). Há dois atributos associados que levaram à multiplicação de projetos de inclusão visual: um de mercado e outro social - houve o barateamento dos equipamentos de fotografia, áudio e vídeo e uma crescente importância das imagens no mundo contemporâneo, bem como no consumo delas pela sociedade.

No Brasil, o $1^{\circ}$ Encontro de Inclusão Visual do Rio de Janeiro ocorreu em 2004, e deu-se como parte de um evento maior, o FotoRio, evento internacional de fotografia organizado pelo fotógrafo e antropólogo Milton Guran. O evento reuniu fotógrafos, lideranças comunitárias, pesquisadores, educadores e interessados na utilização da fotografia como um instrumento de conhecimento, de valorização da autoestima e de comunicação social por parte de moradores de comunidades populares. Desde então, esse encontro vem acontecendo anualmente com o objetivo de "formar uma rede, a fim de fortalecer uma atuação coletiva voltada para uma 'valorização da autoestima' e desenvolvimento de um olhar mais apurado" (GAMA, 2009, p. 4-5), estimulando uma dinâmica de representação e autorrepresentação própria que tensiona estigmas e repensa formas de inclusão social dos participantes por meio da imagem.

Uma das iniciativas que faz parte dessa rede de inclusão é o Projeto Alfabetização Visual, atividade extensionista do Centro Universitário SENAC, em São Paulo. João Kulcsár, coordenador do projeto, é quem toma a frente dessa e de outras ações de inclusão visual desde a década de 1990, trabalhando temáticas diversas no ensino da fotografia, tais como imigração, consciência negra, sistema penitenciário e socioeducativo, comunidades populares e favelas, mulheres e cidadania, meio 
ambiente, envelhecimento e terceira idade, direitos humanos, formação de professores, entre outras2. Kulcsár tem uma experiência muito rica no campo prático da fotografia, especialmente no que diz respeito ao processo de democratização da imagem e ao conceito de visual literacy, ou letramento visual, trabalhado por ele em sua trajetória acadêmica.

Em 2008, dois estudantes cegos, alunos dos Espaço Braille do SENAC-SP, solicitaram a Kulcsár capacitação na prática fotográfica. Desde então o projeto com deficientes visuais passou a acontecer através de oficinas pontuais entre jovens que desejavam aprender a fotografar, atividades que estão conectadas ao currículo do curso de Bacharel em Fotografia, no qual Kulcsár é docente. Foi uma ação de duas vias: de um lado as oficinas capacitavam os estudantes do bacharelado em projetos sociais a partir da metodologia de alfabetização visual; de outro, desenvolvia a fotografia participativa com pessoas cegas como forma de expressão e inclusão social.

A súmula proposta por Kulcsár de experimentar a fotografia por meio da cegueira/deficiência visual é a possibilidade de conhecer as imagens visuais de outras maneiras, seja por parte de pessoas cegas ou com deficiências visuais, seja pela experiência de pessoas videntes3. No texto de curadoria de uma das exposições produzidas4 no âmbito do projeto, Kulcsár nos questiona:

Essa atividade provoca questões: como os deficientes visuais fotografam? Por que querem fotografar? Quando perguntados, afirmam que é pelas mesmas razões que todos fotografam: para guardar o momento, se expressar, compartilhar com os outros, suprir uma necessidade básica do ser humano de produzir e consumir imagens, enfim, para se sentirem participantes dessa sociedade de hipervisibilidade. Ao dispararem o botão da câmera, pessoas com deficiência visual propõem uma discussão além da técnica, estética e ética da fotografia, transformam o ato de fotografar num acontecimento político e, em nossa sociedade imagética, nos mobilizam a de fato ver essas imagens. Para acompanhar cada uma das imagens expostas, visando dar acesso amplo à mostra, foram produzidas pranchas táteis, audiodescrições e textos em braille, disponiveis a todos. Além disso, ao lado de cada prancha tátil, por meio de um código QR, é possivel acessar os vídeos com depoimentos de cada um dos autores aqui representados. Antes de ver a mostra, convidamos você a parar, fechar os olhos, respirar, ouvir e explorar as fotografias produzidas para fruir e transver o mundo com a experiência intensa de outros sentidos.

\footnotetext{
${ }^{2}$ Mais informações sobre esses projetos podem ser acessadas na página do Alfabetização Visual, disponivel em http://www1.sp.senac.br/hotsites/lapascipiao/alfabetizacao/. Acessado em: julho de 2017.

${ }^{3}$ Como sinalizado por Sautchuk (2003), aqui o termo vidente é também utilizado no sentido de pessoa dotada de visão, de acordo com a terminologia utilizada pelos cegos.

${ }^{4}$ Exposição Transver: Fotografias produzidas por deficientes visuais, realizada pela Pinacoteca do Estado de São Paulo e Projeto Alfabetização Visual. São Paulo, 2015.
} 
A fotografia cega ${ }^{5}$ nos convida a acionarmos nosso corpo inteiro, a estarmos atentos a como apreendemos e aprendemos acerca das imagens e seus processos. Como Kulcsár argumenta, a fotografia é um instrumento de promoção à acessibilidade porque ela envolve emoções e compreende uma linguagem que já nos é cotidiana. Além disso, "na maioria das vezes, a gente dá mais valor para a visão e se esquece dos outros sentidos e, vendo uma foto tirada por um deficiente, você lida com questões como tolerância e diversidade" ${ }^{6}$.

Pensando como o trabalho antropológico é, por um lado, concebido entre ver, ouvir e escrever - e que, como abrevia Oliveira (2000), há uma certa ordem para entendimento do campo por estas três etapas -, talvez devamos considerar outras dimensões de percepção neste trabalho, o que existe nos limiares sensoriais e o que supera o ver, o ouvir e o escrever.

No esforço de compreender um pouco a dinâmica fotográfica entre e com cegos, processo que tem se ampliado para estudos do corpo e subjetividade, deficiência, percepção, movimento humano e emoções, utilizo a própria fotografia como ferramenta de pesquisa. Esse trabalho foi realizado no âmbito do Projeto Alfabetização Visual, em 2015.

Nessa perspectiva proponho refletir sobre a fotografia e, assim, sobre a antropologia, em suas potencialidades de irem além enquanto disciplinas. Questiono, dessa forma, os limites tramados por e para essas áreas. Coloco essa questão não no sentido de delimitação e separação do conhecimento, do que demarca o fim e o início de algo, mas nas linhas tênues e invisíveis que são traçadas entre esses saberes, linhas muitas vezes não ditas, não escritas e não mostradas. Há, por outro lado, certa necessidade dessas linhas serem atravessadas e ultrapassadas. O limite é, por vezes, uma fronteira que precisamos cruzar como forma de estabelecermos diálogos e criarmos novas estratégias de investigação. Como sugere Barthes (1987) sobre a intenção criativa da interdisciplinaridade:

\footnotetext{
${ }^{5}$ Esse é um termo cunhado por um dos fotógrafos deficientes visuais, João Maia, em meu trabalho de campo. Ele assim o define por conta de sua limitação visual. Como fotógrafo que se utiliza de uma câmera profissional, mas sem o controle dos ajustes manuais, e por meio do seu resíduo visual (percepção de vultos e cores), sua fotografia é denominada por ele como cega por conta falta de acuidade visual em sua feitura, mas seu ato de fotografar reconhece que imagem pode ser produzida por meio da sensibilidade e de seus outros sentidos.

${ }^{6}$ Entrevista dada à Rede do Saber - Escola de Formação de Professores Paulo Renato Costa Souza, Governo do Estado de São Paulo. Disponível em: http://www.rededosaber.sp.gov.br/portais/Portals/84/docs/entrevista joao 2.pdf. Acesso em: julho de 2017.
} 


\begin{abstract}
"O trabalho interdisciplinar, tão discutido nos dias de hoje, não consiste no confronto entre disciplinas estabelecidas (nem, de fato, é desejável que assim o seja). Não é parte da interdisciplinaridade, por insuficiência, a continuidade de um assunto, de um "tema" - para isso busca-se em duas ou três ciências. A interdisciplinaridade consiste na criação de um novo objeto que venha a ser nenhum" (BARTHES, 1987, p. 107, tradução minha).
\end{abstract}

Transversalmente, se, por um lado, a fotografia das pessoas cegas envolve uma dimensão integral e integrada do corpo, uma vez que as imagens e seus elementos são produzidos a partir dessa referência - distância focal, composição, profundidade de campo são trabalhados tendo o corpo inteiro do fotógrafo ou fotógrafa como orientação e parâmetro a partir do reconhecimento de seus próprios corpos no fazer fotográfico, e não apenas sua visão -, na antropologia, ao me aproximar dessas pessoas, o processo da pesquisa ocorreu também no tato, no olfato, na escuta ainda mais atenta: o corpo inteiro em evidência.

Em meu campo, eu via e observava com as mãos, ouvidos e nariz, e compartilhava, em alguma dimensão, do invisivel que acortina os olhos. A visão aqui não é necessariamente ver e colocar à prova o que foi visto sobre o que não foi visto, afinal, olhar incessantemente aquilo não visto pelos olhos de meus interlocutores não me leva a ver as coisas de fato.

A dimensão do sentir foi, nesse caso, levada por outro caminho e tornou-se fundamental para interação entre mim e os fotógrafos e fotógrafas cegos e cegas. $O$ tato, por exemplo, descortina a ausência de luz, materializando o referente em imagens outras, não apenas visuais. Evgen Bavcar (2003), filósofo e fotógrafo cego, diz que essa escuridão antes da imagem é o próprio anúncio dela e que a mediação pelo tato compreende tão logo uma imagem real. Se o dizer, verbo que precede a formação de qualquer coisa7, é também cego, as imagens mentais podem se formar e ser visualizadas por meio de outras percepções, que não apenas a visão. Diferentemente do olhar da visão, o olhar do tato, como indica Bavcar (2003, s/n), poderia ser definido como "um olhar chegado, ou encostado, aquele que não provoca ainda a separação inelutável entre o sujeito e o objeto do conhecimento. [...] Em outras palavras, a proximidade tátil é o mais seguro sinal de uma existência real".

Aproximando essa reflexão do fazer antropológico, ao invés de pensarmos que ao vermos estamos em um mundo dado e objetivo de modo a objetivarmos

\footnotetext{
${ }^{7}$ Referência às palavras de Evgen Bavcar: "O verbo é, então, cego: ele nos fala do lugar em que surge uma gênese primeira da imagem. É desse modo que, se queremos ir às origens das imagens visuais, nós chegamos forçosamente ao espaço do invisível, este do verbo, e à noite que precede o dia das figuras conhecíveis" (BAVCAR, 2003, s/n)
} 
também as informações de nossas pesquisas pelo distanciamento entre o nosso olhar e as coisas, devemos considerar, porventura, que "os dados etnográficos são", na realidade, "permeados por subjetividades desde a hora que nos deparamos com eles até a hora em que vamos falar sobre eles" (GAMA, 2016, p. 128). Mesmo sendo um desafio teórico-metodológico, considerar um corpo inteiro e integrado foi fundamental para acessar os dados desta pesquisa como parte de uma "experiência incorporada e interconectada". Isso também gera inúmeras outras questões, como aponta Gama:

\begin{abstract}
"A maneira como as pessoas dão sentido ao mundo transpassa a visão e abrange uma mistura de sentidos. Atentar para a importância deles significa entender que há muitas outras formas de experimentar e expressar nossas vivências antropológicas, ainda minimamente exploradas. Que importância estamos dando aos elementos sensoriais experimentados em campo? Como os utilizamos e os engajamos em nossas etnografias? Que implicações abordá-los nos apresenta? Que limites precisam ser expandidos para acolhê-los? O que significa escolher apenas um meio (a escrita) ou mesmo um sentido (a observação) como essencialmente importante para a descrição etnográfica? Que impacto teria no estilo etnográfico uma produção de conhecimento que deslocasse ou mesmo subvertesse a combinação de meios e sentidos? Seria possível apresentar o que vemos em sons; ou o que cheiramos em formas tácteis, como fazemos com os demais sentidos através da visão? Por que seria a visão/a escrita a única forma de expressão possível, ou melhor, confortavelmente aceitável para a produção do conhecimento antropológico? Por que a obsessão pelo discurso verbal quando, sabemos, em nossas imersões no campo, somos sobrecarregados de informações e conhecimentos apreendidos de forma corporificada, através de diferentes emoções e sentidos?" (GAMA, 2016, p. 128).
\end{abstract}

Experienciando imagens cegas, invisíveis, ou mesmo aquelas não vistas, e experimentando outras percepções que levam a cabo os sentidos, conformar e pensar esse processo em um formato textual é, muitas vezes, um desafio. Há um esforço em registrar o sensível, mas há ainda outro, que é o de materializá-lo como produto da pesquisa antropológica.

Permeadas pela experiência multissensorial em campo, ao lidar com imagens produzidas por pessoas com deficiências visuais e participar um pouco de suas vivências cotidianas, minhas inquietações se resumiram numa pergunta: como transpassar essa diversidade de percepções para uma escrita antropológica e etnográfica? Afinal, escrever sobre as coisas que eu não vi, sobre essas imagens não visuais, era, apesar de tudo, um conhecimento que eu ainda estranhava, considerando que o olhar é tido como um dos principais caminhos para feitura de etnografias. O que eu não estava atenta no início e fui descobrindo nesse processo de conhecer as dimensões da pesquisa era que meu próprio corpo me abria a outras possibilidades de vivenciar o trabalho de campo. Mas disso, o que ficaria em meu texto? Ou, como também questiona Sequeira (2010, p. 55), "como tratar dessa 
história que se liquefaz, borrando qualquer registro ou traço de orientação, dentro do que consideramos como lógico numa estrutura narrativa?".

\title{
REVER A ESCRITA ANTROPOLÓGICA E VISUALIZAR ANTROPOLOGIAS
}

\begin{abstract}
"Raras são as imagens que escapam dessa significação forçada. Raras são as que não sofrem curto-circuito quando as fazemos significar à força, quando as fazemos passar por uma ideia, qualquer que seja - principalmente pela ideia da informação ou testemunho. A antropologia moral passou por aí. (...) A maioria das fotos atuais não reflete senão a miséria "objetiva" da condição humana. Não há tribo primitiva sem seu antropólogo, não há homeless no meio de seus dejetos sem um fotógrafo imediatamente surgido para imortalizá-lo na película. Ora, a miséria e a violência nos tocam ainda menos porque elas nos são significadas e mostradas abertamente. É a lei do imaginário. É preciso que a imagem nos toque por ela mesma, que ela nos imponha sua ilusão específica, sua língua original, para que algum conteúdo nos afete"(BAUDRILLARD, 2002, p.147-148).
\end{abstract}

O pensamento do filósofo Jean Baudrillard (2002) em "A fotografia ou a escrita da luz: literalidade da imagem" nos ajuda a refletir sobre construções e representações que se consolidaram na Antropologia, seja por textos, seja por imagens. Essa relação entre texto e imagem na disciplina é marcada desde a sua consolidação enquanto área do conhecimento. Ela coincide, portanto, com os marcos dos primeiros registros visuais e imagéticos, seja pelo surgimento, no século XIX, das placas de daguerreótipos enquanto imagens fixas, seja pelas primeiras películas cinematográficas que buscavam documentar, de forma breve e limitada, acontecimentos do cotidiano.

Esse paralelismo conflui com o desenvolvimento da antropologia e dos estudos e técnicas da imagem, estudos muito marcados pela reprodutibilidade técnica e pela transformação digital. E mesmo que se aproximem temporal e historicamente, as ciências sociais mantiveram uma postura de distanciamento e estranhamento quanto ao uso das imagens como dados etnográficos. O que eram, então, as imagens na pesquisa?

Por muito tempo a imagem não foi mais do que um dos instrumentos de acesso aos dados etnográficos, muito considerada como apenas auxiliar nesse processo. Nesse sentido, Ribeiro (2005) resume bem a recepção da utilização de imagens enquanto recurso de pesquisa: sendo o trabalho científico pensado sob o caráter positivista, a busca pela objetividade do conhecimento se deu a partir do distanciamento de noções subjetivas.

"Nesse processo de utilização, as imagens permanecem rigorosamente controladas pelos métodos tradicionais de inquérito. A sua utilização não os modifica. É comumente aceito pela comunidade científica (micromeio dos especialistas) que a 
partir de finais do século XIX inicia sua utilização. A instrumentação científica introduzida no processo de pesquisa é apenas complementar dos métodos tradicionais: funciona como instrumento de prova e controle, de análise minuciosa e detalhada e como bloco de notas extraordinariamente eficaz. É geralmente admitida a eficácia da utilização dos registros cinematográficos e videográficos no estudo dos comportamentos corporais, rituais, materiais que se desenvolvem num determinado espaço e tempo - "atividades exteriores humanas". Às atividades interiores (representações mentais) o acesso sobretudo faz-se por meio da palavra-fala ou com o apoio da palavra-fala (vozes locais). Daí a importância dos registros de áudio. Essa é uma prática antiga que remete às primeiras expedições científicas e à realização pioneira do trabalho de campo" (RIBEIRO, 2005, p. 625).

Como não podemos assegurar a recepção e a leitura das imagens produzidas, o texto torna-se o principal suporte onde se configura o produto controlado pelo etnógrafo, a etnografia. Cabe considerar que essa estabilidade do texto pode ser um caminho ilusório à medida que não somos capazes de regular totalmente a interpretação dos leitores, considerando seu caráter de agência no acesso às ideias por meio da linguagem escrita.

A relação texto-imagem na antropologia ainda tensiona a dimensão da autoria e da autoridade nesse processo de feitura etnográfica: se aquela remete unilateralmente a um autor - um texto etnográfico enunciado por um indivíduo -, as imagens são quase sempre submetidas ao referente que elas apresentam (CAIUBY, 2008). A escrita etnográfica envolve, assim, estratégias de representar autoridade como forma de promover uma verdade no texto.

\footnotetext{
"Imagens, especificamente as que resultam das modernas técnicas de reprodução, como as fílmicas ou fotográficas, são signos que pretendem completa identidade com a coisa representada, como se não fossem signos. Iludem-nos em sua aparência de naturalidade e transparência, a qual esconde os inúmeros mecanismos de representação de que resultam. Eficientes na comunicação simbólica, sem constrangimento sintático, estas imagens podem ser eloquentes. Por isso mesmo elas mantêm com o discurso verbal - em que o significado parece claro e manifesto uma relação tensa, como uma disputa de território. Se o sentido do texto nos dá a impressão de ser único e fixo (embora seja, também ele, passível de várias leituras) e capaz de abstrações e generalizações, imagens têm uma natureza paradoxal: por um lado, estão eternamente ligadas a seu referente concreto, por outro, são passíveis de inúmeras "leituras", dependendo de quem é o receptor. De modo cada vez mais frequente, as imagens vêm sendo estudadas como forma de linguagem. Entretanto, na relação imagem/palavra, a tendência foi por muito tempo associar a imagem à natureza e a palavra à convenção. Este parece ser um dos motivos que afastaram os cientistas sociais de uma maior proximidade com o estudo de imagens"(CAIUBY, 2008, p. 456 e 457$)$.
}

Isso indica que raramente a relação entre a antropologia e a antropologia visual foi tranquila: "os antropólogos desconfiaram das imagens ao mesmo tempo em que mantiveram uma secreta esperança de que estas thes resolvessem alguns problemas, como o da objetividade. Mantiveram essa insuportável ambiguidade" (RIBEIRO, 2005, p. 634). Imersa na escrita, a etnografia era a tradução da experiência 
de campo em uma forma inerentemente textual, não sendo "possível compreender os processos da ciência etnográfica separadamente ao debate políticoepistemológico mais geral sobre a escrita e a representação da alteridade" (CAMPOS, 2009, p. 51). A produção do conhecimento antropológico está ancorada no texto escrito e a utilização de outras linguagens, sejam elas literárias, poéticas, imagéticas ou sonoras, prevê uma subordinação à palavra amparada pelo fortalecimento da disciplina em princípios racionais.

A dicotomia entre imagem e palavra começou a ser superada quando surgiram pesquisas que evidenciaram a importância da memória nas sociedades sem escrita (CAIUBY, 2008), ampliando o espectro do que podem ser as imagens - visuais, gráficas, óticas, perceptivas, mentais, verbais - e compreendendo que a sua criação possivelmente coincide com nosso entendimento sobre o surgimento da humanidade: criamos imagens desde que nos entendemos como humanos. Essa aproximação com as imagens perturbou a ordem daquilo que se entendia como projeto de conhecimento estabelecido pela antropologia, afinal, sua afinidade com a Arte e seu envolvimento com a imaginação confrontavam seu caráter científico. Mas, salvo por novas teorias, o pensamento científico, como demonstra Lévi-Strauss (2008, p. 30), pode ser reconhecido sob duas facetas: uma mais ajustada à percepção e à imaginação, e o outra mais afastada dessa intuição sensível.

Na intersecção desses dois modos de pensamento, ao abrirmos esse caráter científico também para a imaginação, podemos começar a questionar os binarismos que ancoram as questões antropológicas, não sendo eles necessariamente opostos, mas complementares (GAMA, 2016). Segundo Gama, questões como essas podem ser chamadas de ético-teórico-metodológicas, pois fazem parte de um mesmo processo e não podem ser pensadas como aspectos separados em nossas pesquisas.

"Campo e escrita, forma e conteúdo, razão e emoção estão sempre misturadas, não podendo ser apartadas para análise. Do mesmo modo, imagens, cheiros, sons, texturas, gostos, palavras e qualquer outro aspecto da cultura e da sociedade são elementos intrínsecos à etnografia, elementos relevantes para a maneira como apreendemos o mundo. Formas colaboram com e/ou refletem o conteúdo de nossas análises (textuais, imagéticas, audiovisuais, sonoras etc)" (GAMA, 2016, p. 117).

Esta é a mesma busca de Samain (2011, p. 30) para "entender melhor o que está em jogo quando a gente fala de duas maneiras de fazer ciência - ou, para ser breve -, quando falamos da razão e da imaginação" nos devolvendo uma questão importante: "será, então, que precisamos de tantas outras seguranças, de tantas outras 'razões' para tomar a sério nossa imaginação?" (SAMAIN,2011, p. 31). 
A imaginação adquire importância nas práticas culturais e sociais, sendo "capaz de definir relações e formas de ver o mundo" (GAMA, 2016, p. 118). Isso é evidenciado em como nos entendemos e como imaginamos serem os outros e o mundo em que vivemos. Gama (2016) aponta, a partir das considerações do antropólogo Anand Pandian, que as imagens têm seu papel na imaginação "indicando que 'sonho' e 'realidade' podem ser pensados como parte de um processo criativo que nos permite lidar com o mundo como algo inventado e imprevisível" (Idem). As imagens nos permitem, então, transitar entre na infinidade de mundos possiveis.

Longe de serem capturadas pela total objetividade, o que se creditou por muito tempo à função da fotografia em oposição ao papel da pintura, as imagens são coisas vivas (BAGGIO, 2013). Além disso, considerando-as como pensantes, Baggio, a partir dos fundamentos de Etienne Samain, aponta três argumentos:

\footnotetext{
"De que toda imagem nos oferece algo para pensar, seja ligado ao real, seja ligado ao imaginário; de que as imagens são portadoras de pensamentos porque veiculam pensamentos de quem as produziu e incorporam pensamentos daqueles que as observaram, configurando-se como um lugar de memória coletiva; e de que as imagens são formas que pensam, dialogam e se comunicam, independentemente de nós" (BAGGIO, 2013, p. 213).
}

Imagem é, assim, participação. Além de não funcionar sem essa relação, ela nos provoca, nos conduz e nos dirige a isso (SAMAIN, 2003). Construímos relação com a imagem a partir do momento que direcionamos nosso olhar a ela, sendo o espectador agente em ver, significar e criar novas imagens a partir de uma mesma. Ao lidarmos com imagens fixas ou em movimento, para além de as produzirmos, temos o papel central de sermos espectadores convidados à descoberta, e como bem sintetiza Caiuby (2008, p. 465): "se o texto nos diz sobre algo, o filme nos convida a descobrir".

Ao mesmo tempo que nos convida para um campo de estudos possível, a imagem nos aponta "lugares de nosso imaginário para deixar bem claro e reivindicar o fato de que nunca será o equivalente de uma palavra" (CAIUBY,2008, p. 462). Com inúmeras saídas para o conhecimento, as imagens nos mostram caminhos que devemos descobrir e explorar.

"É possível afirmar que se o texto permite o conhecimento pela descrição, as imagens proporcionam conhecimento por meio da familiaridade, aquilo que os ingleses denominam de acquaintance. (...) Imagens favorecem, mais do que o texto, a introspecção, a memória, a identificação, uma mistura de pensamento e emoção. Imagens, como o próprio termo diz, envolvem, mais do que o texto descritivo, a imaginação de quem as contempla. Elementos visuais têm a capacidade de metáfora e sinestesia — relação subjetiva espontânea entre uma percepção e outra que pertença 
ao domínio de um sentido diferente. Podemos associar algumas formas ou objetos a pessoas ou seres específicos, certos cheiros evocam a (466) infância etc. Esta capacidade de metáfora e sinestesia é muito mais acentuada nas imagens quando comparadas ao texto verbal"(CAIUBY, 2008, p. 465).

Muitas vezes não cabem em nossos textos todas as experiências vivenciadas em campo, essas que aprendemos transitando em dimensões não verbais das relações que estabelecemos com nossos interlocutores. Como reflete Caiuby (2008), envolvidos nessas experiências de alteridade, por elas somos afetados. Contudo, o texto escrito estabelece uma hierarquia nítida na produção do conhecimento: primeiro a explicação, depois a descrição e, por último, a experiência (CAIUBY, 2008). Isso se dá porque a antropologia é herdeira de uma tradição logocêntrica e eminentemente verbal, em que, mesmo que a etnografia emerja de uma experiência pessoal do pesquisador em suas percepções, essa particularidade tende a desaparecer no texto. Assim também considera Gama (2016), ao apontar que

\footnotetext{
"Raras são as pesquisas que experimentam e expressam suas informações antropológicas a partir de sons, temperaturas, cheiros, gostos, emoções e incorporações. Ou que proponham formas etnográficas que transmitam a interação complementar entre humanos e não-humanos, consciente e inconsciente, pensamento e sensação de forma não controlada pelo discurso e/ou pela visão" (GAMA, 2016, p. 118).
}

Caiuby (2008) diz que o uso das imagens pode nos auxiliar a perceber nossas experiências individuais em nossas etnografias por promoverem outro tipo de envolvimento, a partir de uma "antropologia que focasse no que significa pertencer a uma cultura com toda a intrincada tessitura de experiências, e suas relações com o que é do domínio do costume e o que é do domínio pessoal" (Caiuby, 2008, p. 470). Não há mais conclusões e afirmações tão determinadas sobre as culturas, mas cada análise se apresenta como uma possibilidade de leitura, interpretação e tradução daquilo. Trata-se de uma nova concepção de conhecimento que não envolve apenas reflexões sobre a experiência, mas a inclui como parte da etnografia.

O final do século XX, com a crítica pós-moderna, estimulou não apenas novas formas de escrita, mas também diferentes caminhos de leitura antropológica permeados pela abertura às complexas redes de significação, bem como ao posicionamento dos atores sociais envolvidos (CAIUBY, 2008). O que busco refletir aqui não é o confronto entre texto e imagem na prática antropológica, nem a sobreposição de uma linguagem sobre a outra, mas o entendimento de que se tratam de suportes distintos que possuem engajamentos diferentes na produção de conhecimento. 


\title{
OUTROS CAMINHOS POSSÍVEIS: DA ANTROPOLOGIA PELA VISÃO À ANTROPOLOGIA SENSORIAL
}

Quando falamos de imagens, de forma automática, nos remetemos à visão. Pensar uma antropologia por meio de imagens pode causar certa confusão ou desconforto, uma vez que estamos criticando a predominância da visão no fazer antropológico. O que temos de ter em mente, então, é que as imagens, mesmo que envolvam essa dimensão do olhar, estão além do que vemos. Mas, em um sentido prático, de que forma podemos pensar em antropologias visuais que não sejam direcionadas por esse caráter oculocêntrico da disciplina? O antropólogo James Clifford (1991) esboça outras abordagens a partir do que é chamado de visualismo e de estudos dos sentidos em associação às formas de imaginação e classificação em diferentes culturas:

\begin{abstract}
"Outro ponto de inflexão notável na crítica antropológica sob uma perspectiva teórico-política, vem sendo dado pelo visualismo (...). Ong (1967-1977), entre outros, há muito tem dedicado ao estudo dos sentidos, hierarquicamente ordenados através das diferentes épocas e culturas. Argumenta Ong que a visão ocidental das culturas, e inclusive das literaturas, tem predominado acima de evidências sonoras, por exemplo, ou táteis, ou olfativas, ou gustativas. Mary Pratt, por sua vez, observa que as referências odoríferas, predominantes na prosa de todo escritor viajante, permanecem à margem das concepções e dos usos do etnógrafo. No mesmo sentido Frances Yates (1966) argumenta que, no Ocidente, a imaginação taxonômica se encontra fortemente impregnada pelo visualismo, pela apreensão da natureza, constituindo culturas como se fossem teatros da memória e formações no espaço" (CLIFFORD, 1991, p. 40, tradução minha).
\end{abstract}

Pink (2006) aponta que a crise da representação na antropologia, iniciada na década de 1980, convidou etnógrafos não só a repensarem criativamente formas de escrita do texto antropológico, mas inspirou novos caminhos para representar aspectos sensoriais incorporados pela cultura, pelo conhecimento e pela experiência. A autora sugere que as experiências visuais, compreendidas pelo conhecimento por meio de imagens, interessam particularmente a antropologia porque estão relacionadas com experiências sensórias, com o conhecimento e com a noção de representação (PINK, 2006). Mesmo com essas ideias em mente, os antropólogos visuais demoraram a reconsiderar as visualidades e as experiências sensoriais em suas incursões etnográficas por meio de imagens que produzem conhecimento. A pergunta que viria a ter grande importância nesse momento trataria do que entendemos como vivências e quais suas implicações na prática antropológica e na vida social de um determinado grupo, mostrando que a experiência e o conhecimento são corporificados, encorporados e sensoriais. 
"Contudo, os antropólogos visuais (inclusive eu) deram apenas um rápido reconhecimento aos outros sentidos em seus argumentos para uma metodologia etnográfica visual (por exemplo, Banks 2001; Pink 2001a). Aqueles que discutiram os sentidos defenderam o potencial do filme etnográfico para representar outras experiências sensoriais (MacDougall 1998, 2000; Ruby 2000a), a capacidade do filme de invocar a experiência sensorial em seus espectadores (Grimshaw 2001; Stoller, 1997), o uso de metodologias inovadoras na antropologia visual para representar a experiência sensorial (Grimshaw e Ravetz 2005) ou a materialidade de artefatos visuais e suas qualidades sensoriais (Edwards 1999). Além disso, os antropólogos visuais prestaram pouca atenção à questão do que é a experiência. No entanto, há muito tempo os antropólogos têm se interessado pela questão da "experiência" como uma questão empírica, teórica e metodológica. Como experimentamos? O que é a experiência? Como pode ser entendida teoricamente e como podemos ir pesquisando e representando-a?

[...] O trabalho de campo sensorial envolve não apenas tentar "sentir" as experiências de outras pessoas, mas também aprender as categorias que constituem seu sistema de significação sensória e possivelmente as diferenças entre estas e as do antropólogo. Ao enfatizar a relação entre a prática e os significados sensoriais, Geurts demonstra como a compreensão da experiência e do conhecimento sensorial de outras pessoas não é, de todo modo, uma questão direta. Como nossas práticas rotineiras são moldadas por significados culturalmente específicos atribuídos a certos cheiros, sons, toques, paladar e assim por diante (2002:235), culturalmente constituída, a sensorialidade pode afetar "as características mais básicas de nossas habilidades de julgar uns aos outros" (PINK, 2006, p. 41 e 47, tradução minha).

Falando sobre e com imagens, a experiência do olhar é multisensorializada quando elas permitem em sua essência "uma descentralização do sujeito, uma simultaneidade que produz a proliferação de pontos de vista" (GONÇALVES, 2013, p. 173), envolvendo quem produz, quem é imaginado e quem é espectador. Ainda, somos furtados por uma forma de conhecer que envolve nossos corpos em sua constituição: lidando com a possibilidade de nos projetarmos pelas imagens que vemos, "a sensação de presença em um filme", por exemplo, "não é uma ilusão, mas 'uma alucinação que é real' em seus efeitos'" (PINK, 2006, p. 178).

"Enfatiza-se, assim, um caráter subjetivo de um conhecimento que 'procede das emoções', conectando, de uma só vez imagem e conhecimento através dos sujeitos do cinema: quem filma, os filmados e o espectador. Deste modo, a perspectiva, o modo de olhar no cinema, engendra um conhecimento imagético ancorado numa forma particular de conhecer que, retomando mais uma vez Eisenstein, diríamos, agora, conhecimento sensorial" (GONÇALVES, 2013, p. 172).

Essa representação multissensorial da experiência é possível por meio de imagens quando consideramos serem os nossos sentidos não sobrepostos, mas integrados. Podemos acionar pela visão, cheiros, texturas, sensações, emoções. Não se trata, de forma simplista, de considerar a experiência do olhar como sinestésica, mas de fato interconectada com o corpo inteiro, compreendendo a totalidade do sistema sensorial.

Em vez de separar a visão dos outros sentidos, assumindo seu caráter dominante na construção do conhecimento, no entendimento das funções do nosso 
corpo e nas nossas práticas sociais e culturais, talvez devêssemos prestar mais atenção em como os outros sentidos também estão envolvidos nesses processos. Pink (2006, p. 48) aponta uma questão a ser resolvida na antropologia visual: "como ela pode engajar os outros sentidos e como podemos investigar e representar os aspectos visuais e não visuais das experiências sensórias?". Neste mesmo sentido, Gama (2016) sugere que

\begin{abstract}
"Contar uma história através de formas multissensoriais é investir em meios de comunicação que ultrapassem as palavras. E isso significa pensar como, para quem, mas também onde apresentar nossos trabalhos. Os ambientes onde as pessoas (antropólogas e interlocutoras) se encontram, assim como os ambientes potenciais de recepção dos nossos trabalhos têm significado. A mudança do local, ou mesmo do ponto de vista, muda a compreensão do que acontece em nossa frente. [...] Experimentar e expressar emoções são parte de um mesmo processo, vivido através do corpo, que ocorre na relação com nossas interlocutoras. Ou seja, tal processo de experimentação e expressão de emoções e conhecimentos é resultado da interação de uma rede de agentes que se automodulam consciente e inconscientemente, seja no que chamamos de 'mundo real' seja em nossas imaginações. Assim, atentar para os sentidos implica em dois movimentos: atentar para os diferentes sentidos e compreender que as experiências são mediadas por eles" (GAMA, 2016, p. 127).
\end{abstract}

Não opostas, podemos explorar de forma ampla combinações entre texto e imagens, fixas ou em movimento, na representação de experiências sensórias nas etnografias produzidas. Além da aceitação de diferentes suportes para circulação e recepção de nossos trabalhos, como textos em multimídia, realidades aumentadas, instalações, seria mais justo também nos aceitarmos em uma posição de diálogo com outras áreas do saber e outras formas de pensamento, seja a Literatura, a Arte, a Performance, o Cinema, a Biologia, a Psicologia etc.

Unindo diferentes figuras de linguagem e uma diversidade de argumentos teóricos, podemos aproveitar o que de melhor nos proporcionam as formas visuais e a escrita antropológica para apresentar novas teorias etnográficas que emergem das representações de nossas experiências sensoriais. Assim, a preocupação repousa não necessariamente em quem está fazendo antropologia, ou onde ela está, mas em que tipo de antropologia tem sido feita (MADAN, 1996, apud PEIRANO, 2006). Se acreditamos que etnografia é experiência, que as nossas pesquisas sejam um convite a experimentá-la.

\title{
REFERÊNCIAS
}

BAGGIO, Adriana Tulio. Imagens que pensam, que sonham, que sentem. Uma proposta ousada? Galaxia (São Paulo, online), n. 25, p. 211-216, 2013. 
BARTHES, Rolland. Jovenes investigadores In: El susurro del lenguaje. Barcelona: Paidós [1984] 1987.

BAUDRILLARD, Jean de. A fotografia ou a escrita da luz: literalidade da imagem. In A troca impossível. Tradução de Cristina Lacerda e Teresa Dias Carneiro da Cunha Rio de Janeiro: Nova Fronteira. p. 143-150, [1999] 2002.

BAVCAR, Evgen. 0 Corpo, Espelho Partido da História. In NOVAIS, Adalto (Org.) 0 homem-máquina. A ciência manipula o corpo. São Paulo: Companhia das Letras, 2003.

CAIUBY NOVAES, Sylvia. Imagem, magia e imaginação: desafios ao texto antropológico. Mana 14 (2). p. 455-475, 2008.

CAMPOS, Rogério Schimidt. Fotografia e alteridade - Os limites das linguagens na experiência etnográfica. Dissertação de mestrado. 86p. Departamento de Antropologia. Programa de PósGraduação em Antropologia Social. Brasília: Universidade de Brasília, 2009.

CLIFFORD, James. Introducción: verdades parciales. In: CLIFFORD, J.; MARCUS, G. E. (Eds.) Retóricas de la Antropología. Madrid: Júcar Universidad. p. 25-60, [1986] 1991.

GAMA, Fabiene A auto-representação fotográfica em favelas e 0 movimento de inclusão visual. Revista Anthropológicas, v. 20(1), p. 199-217, 2009.

Sobre emoções, imagens e os sentidos: estratégias para experimentar, documentar e expressar dados etnográficos. RBSE - Revista Brasileira de Sociologia da Emoção (Online), v. 15, p. 116-130, 2016.

GONÇALVES, Marco Antônio. Sensorial Thought: cinema, perspective and Anthropology. Traduzido pelo autor. Vibrant, 9(2), p. 160-183, 2013.

LÉVI-STRAUSS, Claude. A ciência do concreto. In 0 pensamento selvagem. Tradução de Tânia Pellegrini. Campinas, São Paulo: Papirus, p. 15-50, [1969], 2008.

MENDES, Ricardo. Fotografia e inclusão (social): revendo experiências das últimas três décadas. Revista d'Art, São Paulo, v. 12, p. 71-75, 2005.

OLIVEIRA, Roberto Cardoso de. 0 trabalho do antropólogo: olhar, ouvir e escrever in 0 trabalho do antropólogo. Brasília: Paralelo 15. São Paulo: Editora UNESP. p. 17-36, 2000.

PEIRANO, Mariza. Onde está a antropologia? In antropologia. São Paulo: Zahar Editor. p. 15-36, 1997.

A teoria vivida e outros ensaios de

PINK, Sarah. The future of visual anthropology: engaging the senses. London New York: Routledge. 166p. 2006.

RIBEIRO, José da Silva. A antropologia visual, práticas antigas e novas perspectivas de investigação. Revista de Antropologia, São Paulo, USP, v. 48, n². p. 613-648, 2005.

SAMAIN, Etienne Ghislain. Antropologia de uma imagem 'sem importância'. Ilha. Revista de Antropologia (Florianópolis), Florianópolis, v. 5, n.1, p. 47-64, 2003. 
p. 29-51, 2011.

As 'Mnemosyne(s)' de Aby Warburg: entre antropologia, imagens e arte. Revista Poiésis, v. 17,

SAUTCHUK, Carlos. Deficiência e transcendência: a cegueira na modernidade ocidental. 119p. Dissertação de mestrado. Departamento de Antropologia, Programa de Pós-Graduação em Antropologia Social. Brasília: Universidade de Brasília. 2003.

SEQUEIRA, Alexandre Romariz. Entre Lapinha da Serra e o Mata Capim: fotografia e relações de trocas simbólicas. 118p. Dissertação de Mestrado. Escola de Belas Artes, Programa de Pós-Graduação em Artes. Belo Horizonte: Universidade Federal de Minas Gerais, 2010.

Recebido em 30 de julho de 2017.

Aprovado em 13 de dezembro de 2017. 